\title{
May mothers given warfarin breast-feed their infants?
}

\author{
M L'E ORME, P J LEWIS, M DE SWIET, M J SERLIN, R SIBEON, J D BATY, \\ A M BRECKENRIDGE
}

British Medical fournal, 1977, 1, 1564-1565

\begin{abstract}
Summary
Warfarin was measured with a sensitive and specific method in the plasma and breast milk of 13 mothers. Less than $0.08 \mu \mathrm{mol}$ warfarin per litre $(25 \mathrm{ng} / \mathrm{ml})$ of breast milk was found in each instance. Seven of the mothers were breast-feeding their infants, in none of whom was warfarin detected in the plasma; furthermore, in three the British corrected ratio of the plasma was appreciably less than that of the mother and was within the expected range. We conclude that nursing mothers given warfarin may safely breast-feed their infants.
\end{abstract}

\section{Introduction}

Nursing mothers given anticoagulants by mouth are often advised against breast-feeding because of the risk of transferring the drug to the infant. More mothers are now seeking advice about this because of the widespread use of oral anticoagulants post partum and because of the increased popularity of breastfeeding.

This problem has been investigated previously, but for several reasons there is little consensus on whether oral anticoagulants are present in breast milk. Firstly, the standard of clinical documentation in many reports leaves much to be desired. Secondly, analytical procedures used often lack sensitivity or specificity or both. Thirdly, many of the cited data are derived from animals.

We have designed a two-part study to investigate whether warfarin is excreted in clinically appreciable amounts in breast milk. In the first part of the study concentrations of warfarin were measured in the plasma and breast milk of mothers taking warfarin who did not breast-feed their infants. In the second part, mothers taking warfarin and their infants who were breast-fed were investigated. Informed consent was obtained in all cases, and the protocol was approved by the ethical committee.

\section{Methods}

PATIENTS

Six women aged 20-43 years were included in the first part of the study. Three had developed deep vein thrombosis during the second trimester of pregnancy, and the other three were given warfarin after

University of Liverpool, Liverpool L69 3BX

M L'E ORME, MD, MRCP, senior lecturer in clinical pharmacology M J SERLIN, MB, MRCP, lecturer in clinical pharmacology R SIBEON, HNC, AIMLS, senior technician

J D BATY, PHD, lecturer in medicine (now at University of Dundee)

A M BRECKENRIDGE, MD, FRCP, professor of clinical pharmacology

Institute of Obstetrics and Gynaecology, Queen Charlotte's Hospital for Women, London W6 OXG

P J LEWIS, MD, MRCP, senior lecturer in clinical pharmacology

$M$ DE SWIET, MD, MRCP, consultant physician delivery because of previous pulmonary embolism while taking contraceptive steroids. Warfarin treatment was begun 24 hours after delivery with a loading dose of 30 or $40 \mathrm{mg}$ followed by a daily maintenance dose of 5-11 mg (see table I). At least three days after starting treatment, and four hours after a dose, samples of blood $(10 \mathrm{ml})$ were taken from each mother into sodium citrate $(10 \% \mathrm{v} / \mathrm{v})$. The plasma was separated by centrifugation and stored at $-20^{\circ} \mathrm{C}$. Blood was taken from two women on two occasions on separate days. When the blood sample was taken a sample of breast milk $(20 \mathrm{ml})$ was expressed and stored at $-20 \mathrm{C}$ until analysed.

TABLE I-Results of first part of study (women who did not breast-feed their infants)

\begin{tabular}{|c|c|c|c|c|c|}
\hline $\begin{array}{l}\text { Case } \\
\text { No }\end{array}$ & $\begin{array}{c}\text { Days } \\
\text { post } \\
\text { partum }\end{array}$ & $\begin{array}{c}\text { Warfarin } \\
\text { dose } \\
\text { (mg/day) }\end{array}$ & $\begin{array}{c}\text { Plasma } \\
\text { warfarin } \\
\text { concentration } \\
(\mu \mathrm{mol} / \mathrm{l})\end{array}$ & $\begin{array}{l}\text { British } \\
\text { corrected } \\
\text { ratio }\end{array}$ & $\begin{array}{c}\text { Warfarin } \\
\text { concentration } \\
\text { in breast milk } \\
(\mu \mathrm{mol} / \mathrm{l})^{*}\end{array}$ \\
\hline $\left.\begin{array}{l}1 \\
2 \\
3 \\
4 \\
5 \\
6\end{array}\right\}$ & $\begin{array}{l}6 \\
4 \\
8 \\
7 \\
9 \\
6 \\
6 \\
4\end{array}$ & $\begin{array}{r}5 \\
8 \\
5 \\
4 \\
8 \\
11 \\
10\end{array}$ & $\begin{array}{l}3.9 \\
8.5 \\
8 \cdot 1 \\
5 \cdot 2 \\
4 \cdot 9 \\
4.9 \\
3.9 \\
4 \cdot 1\end{array}$ & $\begin{array}{l}1 \cdot 4 \\
2 \cdot 1 \\
3.1 \\
2.1 \\
1.9 \\
2 \cdot 1 \\
1.5 \\
1.9\end{array}$ & $\begin{array}{l}0 \\
0 \\
0 \\
0 \\
0 \\
0 \\
0 \\
0\end{array}$ \\
\hline
\end{tabular}

${ }^{*} 0=<0.08 \mu \mathrm{mol} / 1$.

Conversion: $S I$ to traditional units-Warfarin concentrations in plasma and milk: $1 \mu \mathrm{mol} / 1 \approx 0.31 \mu \mathrm{g} / \mathrm{ml}$

Seven women aged 20-34 years were included in the second part of the study. Four had developed deep vein thrombosis during the second trimester, two had had artificial heart valves inserted before pregnancy, and one developed cerebral venous thrombosis during the last trimester. These patients were treated with heparin during the last four weeks of pregnancy. Twenty-four hours after delivery warfarin was restarted with a loading dose of $30-40 \mathrm{mg}$ followed by a maintenance dose of $2-12 \mathrm{mg}$ daily (see table II). Samples of blood and milk were taken as in the first part of the study, four mothers being studied on two separate days, and one on three separate days. In addition, a blood sample was obtained by venepuncture from all seven infants about one and a half hours after breast-feeding. This interval was chosen because plasma warfarin concentrations in adults are at their maximum one to one and a half hours after ingestion. ${ }^{1}$ Plasma warfarin concentration was assayed in each sample, and in three infants the prothrombin time was also measured. None of these infants had received vitamin $\mathrm{K}$ before or during the study.

\section{PLASMA WARFARIN ESTIMATION}

Plasma warfarin concentrations were measured by the method of Kaiser and Martin, ${ }^{2}$ a ${ }^{63} \mathrm{~N}$ electron capture detector fitted to a Pye series 104 gas-liquid chromatograph being used. Warfarin was measured to a concentration of $0.08 \mu \mathrm{mol} / 1(25 \mathrm{ng} / \mathrm{ml})$ of plasma, the recovery of warfarin being $83 \%$.

\section{ESTIMATION OF WARFARIN IN BREAST MILK}

Samples of breast milk $(1 \mathrm{ml})$ containing warfarin were acidified $(0.1 \mathrm{ml} 10 \mathrm{M}$ sulphuric acid) and extracted with $20 \mathrm{ml}$ chloroform/ methanol $(2 / 1 \mathrm{v} / \mathrm{v})$. The tubes were vortex-mixed for three minutes and cooled on ice for 20 minutes to aid separation of emulsions formed. The upper (aqueous) layer containing unwanted lipids was then carefully removed by aspiration. Tenth-normal sodium hydroxide 
TABLE II-Results of second part of study (mothers and breast-fed infants)

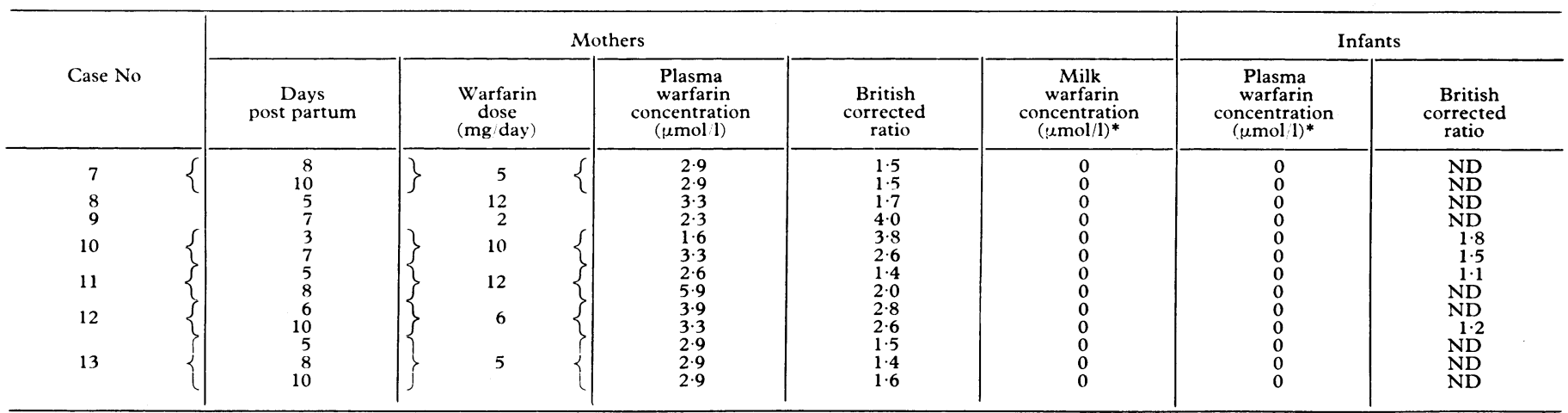

Conzersion: SI to traditionul units-Warfarin concentrations in plasma and milk: $1 \mu \mathrm{mol} / 1 \approx 0.31 \mu \mathrm{g} / \mathrm{ml}$. $*_{0}=<0.08 u \mathrm{~mol} / \mathrm{l} . \quad \mathrm{ND}=$ Not done.

$(4 \mathrm{ml})$ was added, and after vortex-mixing for two minutes followed by refrigerated centrifugation at $2000 \mathrm{rpm}$ for 10 minutes the upper (aqueous) layer was retained. This was washed with $10 \mathrm{ml}$ hexane, then centrifuged at $2000 \mathrm{rpm}$ for 10 minutes, the upper organic phase being removed by aspiration and discarded. To the aqueous layer was added $0.1 \mathrm{ml} 10 \mathrm{M}$ sulphuric acid and $10 \mathrm{ml}$ chloroform, and extraction was carried out by vortex-mixing for two minutes followed by centrifugation. The upper aqueous layer was removed by aspiration and the lower organic layer retained and evaporated to dryness in a water-bath at $40^{\circ} \mathrm{C}$ under a stream of oxygen-free nitrogen. The walls of the tubes were washed with $1 \mathrm{ml}$ acetone (Aristar grade) and again evaporated to dryness. Further analysis was carried out as for plasma samples.

Recovery of warfarin from breast milk was $71 \%$, and warfarin could be measured to a concentration of $0.08: \mathrm{mol} / 1(25 \mathrm{ng} / \mathrm{ml})$. The homogeneity of the derivative used in both plasma and breast milk methods was checked by analysis on an AEI MS12 mass spectrometer.

\section{ANTICOAGULANT EFFECT}

The anticoagulant effect of warfarin in both mothers' and infants' plasma was estimated as the British corrected ratio (BCR) with use of the standard reference reagent ${ }^{3}$ the British comparative thromboplastin.

\section{Results}

Table I gives the results of the first part of the study. Plasma warfarin concentrations ranged from 3.9 to $8.5 \mu \mathrm{mol} / 1(1.2$ to $2.6 \mu \mathrm{g} / \mathrm{ml})$ and BCR from 1.4 to 3.1 (therapeutic range 1.8 to 3.0 ). In none of the six women was warfarin detected in any sample of breast milk, and thus the second part of the study was carried out (table II). Again, in none of the seven women was warfarin detected in the breast milk, although it was easily detectable in plasma at concentrations of $1.6-5.9 \mu \mathrm{mol} / 1(0.5-1.8 \mu \mathrm{g} / \mathrm{ml})$. In none of the plasma samples from the seven infants was warfarin detected. In the three infants in whom the BCR was measured it was less than the maternal value.

\section{Discussion}

These results show that mothers taking warfarin may safely breast-feed their infants. We could not detect warfarin in either maternal milk or infants' plasma at up to 10 days after delivery. Furthermore, in three infants studied the BCR was appreciably less than the maternal value. The range of BCRs in the three infants $(1 \cdot 1-1 \cdot 8)$ was well within the expected range for newborn infants who have not been given vitamin $\mathrm{K}$ at birth. The plasma warfarin concentrations in the 13 women $(1.6-8.5 \mu \mathrm{mol} / \mathrm{l}$; $0.5-2.6 \mu \mathrm{g} / \mathrm{ml}$ ) were within the range for patients with a prothrombin time within the therapeutic range. ${ }^{4}$

The methods we used to measure warfarin in plasma and breast milk are both sensitive and specific. A sensitivity of
$0.08 \mu \mathrm{mol} / 1(25 \mathrm{ng} / \mathrm{ml})$ in both plasma and breast milk suggests that even if the milk were to have a warfarin concentration of $0.07 \mu \mathrm{mol} / \mathrm{l}(20 \mathrm{ng} / \mathrm{ml})$ and the infant were to drink 1 litre of milk daily insufficient drug $(0.02 \mathrm{mg})$ would be ingested to have a noticeable anticoagulant effect.

The principles underlying the passage of drugs into breast milk are reasonably clear. The mammary gland epithelium is a lipid barrier with protein-lined pores. Water-soluble substances with a molecular weight of 200 or less-ethanol, for examplewill diffuse through and achieve the same concentration in milk as in plasma. A few drugs are actively excreted into milk. Most, however, are weak acids or bases and enter milk in their non-protein-bound, unionised form to achieve concentrations depending on the $\mathrm{pH}$ difference between plasma $(7 \cdot 4)$ and breast milk ( $\mathrm{pH} 7 \cdot 0$ ). Warfarin is a weak acid (pK 5.0) and is strongly bound to plasma proteins $\left(98 \cdot 5-99 \cdot 5^{\circ}\right.$ at therapeutic plasma concentrations). ${ }^{5}$ Thus of the free drug, most will exist in the ionised, non-lipid-soluble form in both plasma and breast milk.

We did not measure the plasma or breast-milk concentrations of warfarin metabolites, but, since the anticoagulant effect of warfarin alcohols (the only active metabolites) is some hundredfold less than warfarin, the possible presence of these substances does not appear to be therapeutically important. Furthermore, on a physiochemical basis it seems unlikely that warfarin alcohols would pass into breast milk if warfarin does not. ${ }^{6}$

Our data apply only to warfarin, and the conclusions should not be extrapolated to other oral anticoagulants. Small amounts of ethyl biscoumacetate have been detected in the milk of mothers taking this drug, ${ }^{7}$ and there has been one report of a breast-fed child of a mother given phenindione developing a large haematoma, the child's prothrombin time being increased.

We gratefully acknowledge financial help from the Peel Medical Memorial Trust, the Nuffield Foundation, and the Mersey Regional Health Authority.

\section{References}

${ }^{1}$ Breckenridge, A M, and Orme, M, Clinical Pharmacology and Therapeutics, 1973, 14, 955 .

2 Kaiser, D, and Martin, R, fournal of Pharmaceutical Science, 1974, 63, 10.

3 Poller, L, Thrombosis et Diathesis Haemorrhagica, 1975, 33, 157.

${ }^{4}$ Breckenridge, A M, and Orme, M, in Biological Effects of Drugs in Relation to their Plasma Concentrations, ed D S Davies and B N C Prichard, p 145. London, Macmillan, 1973.

5 O'Reilly, R A, Fournal of Clinical Investigation, 1967, 46, 829.

${ }^{6}$ Lewis, R J, et al, Fournal of Laboratory and Clinical Medicine, 1973, 81, 925.

' Illingworth, R, Fournal of Obstetrics and Gynaecology of the British Commonwealth, 1959, 66, 487.

${ }^{8}$ Eckstein, H B, and Jack, B, Lancet, 1970, 1, 672.

(Accepted 23 March 1977) 